\title{
Campus Stalls: A Marketplace Specifically for Students College Needs
}

\author{
Bambang Robiin \\ Informatics Engineering Department \\ Univeritas Ahmad Dahlan \\ Yogyakarta, Indonesia
}

\author{
Wahyu Pujiyono \\ Informatics Engineering Department \\ Univeritas Ahmad Dahlan \\ Yogyakarta, Indonesia
}

\begin{abstract}
E-commerce, especially the marketplace in Indonesia is developing very rapidly. This development is in line with people's lifestyles, especially college's student who are accustomed to shopping online. Not all the needs of college's student and the academic community can be accommodated by these marketplaces. Marketplaces have become too general and large to meet the needs of those who are segmented and local. This research aims to design and develop a marketplace called campus stalls. The subjects in this study were students of Universitas Ahmad Dahlan, Yogyakarta. This research method consists of five stages. these steps are data collection, analysis, design, implementation and evaluation. This research has been successfully carried out by creating a web based marketplace application to meet the needs of college's student called campus stalls. The usability test score was 4.62 from a scale of 5 . The results of this test indicate that the campus marketplace web stalls are appropriate and meet user needs.
\end{abstract}

\section{General Terms}

Web application, Ecommerce

\section{Keywords}

marketplace; web application; ecommerce; campus stalls; marketplace for student college;

\section{INTRODUCTION}

E-commerce is a commerce organized through electronic infrastructure such as computer networks and the internet. Transactions that were originally done traditionally are now replaced by electronic systems [1]. E-commerce is developing very rapidly [2]. One form of e-commerce that is popular today is a marketplace. A marketplace is a term consisting of the words "market" and "place" which means a meeting place between supply and needs [3].

Marketplace in Indonesia is also growing very rapidly. Many companies set up marketplaces and compete for customers by offering a variety of advantages of both products and delivery services [4]. There are many marketplaces that are growing rapidly and can be received well by the people in Indonesia such as lazada, tokopedia, bukalapak, blibli, sophie, etc. Through the marketplace, it allows sellers and buyers from various regions to meet online and make transactions. The development of the marketplace is also in line with the development of people who are familiar with utilizing internet and mobile technology for daily life, including shopping [5].

The existence of the marketplace also supports the creation of prospective new entrepreneurs to get great opportunities because of a market that is not limited by distance and time. It also supports the creation of entrepreneurship among students who are currently equipped with entrepreneurial competencies.

Campus is an educational institution in which there are students, lecturers, and academic community. Campus life is an academic activity carried out by students and lecturers along with all their supporters. Many needs arise from daily activities on campus, both personal needs and organizational needs, both daily needs and incidental needs. Various facilities are provided to support this operation. The surrounding community also feels the positive impact of campus activities. Many opportunities can be taken to improve the economy, such as boarding houses, food stalls, stationery stores, photocopying services, etc. Students, lecturers and academics are a fairly large market segment with various needs.

The strong influence of technology on people's lifestyles including college's student makes them want to fulfill their needs, especially shopping easily, practically and efficiently. Despite the rapid development of the marketplace, there are a number of needs within the campus, especially students that cannot be fully accommodated by the marketplace. For example, a student who has completed his studies has some used items that are still valuable and can be sold to other students. This transaction will be difficult to do in the marketplace. The marketplace becomes a market that is too broad for students to meet segmented and local needs.

The research aims to develop a marketplace that matches the needs and characteristics of students in the campus environment. How to bring together sellers and buyers in the campus environment.

\section{LITERATURE REVIEW}

There are several previous studies that underlie campus stall research as this marketplace is proposed. Research with the title New Solutions for Instant Payment Problems in Indonesia [2]. This research discusses the development of e commerce, especially marketplaces and instant payments that sometimes have problems. This study aims to design an improved payment scheme to overcome the problem of instant payments. This study provides an overview of how online payment methods are sometimes experiencing problems and the crew is given an alternative solution.

Research with the title An e-Marketplace of Healthcare and Social Care Services: the perceived interest [3]. This research develops a segmented marketplace that is in the field of health services and social services based on perceived interest. This study illustrates how a marketplace is developed for specific services and segmented markets.

Research with the title GuiMarket specification using the Unified Modeling Language [6]. This research aims to design 
UML (Unified Modeling Language) and IDEF0 (Integration DEFinition version 0) for guimarket according to user needs. This study provides an overview of how the design of UML and IDEF0 are made according to user needs.

Research entitled Creating a Marketplace for Multidisciplinary Multi-university Systems Engineering Capstone Projects [7]. This research aims to create a marketplace with multi-disciplinary and multi-university user segmentation for capstones projects. This research illustrates how a marketplace is created for a limited (segmented) market.

Research with the title Customized logistics service and online shoppers' satisfaction: an empirical study [4]. This study aims to determine customer satisfaction with online shopping services with a logistics system that can be adjusted. This research shows that shipping and shipping costs affect customer satisfaction.

Research entitled Creation of a conceptual model for Adoption of Mobile Apps for shopping from E-Commerce sites-An Indian context [8]. This research explores the growth of mobile application users as consumers in India to propose a new conceptual model for adopting ecommerce sites. This study explains how mobile applications meet the needs of certain consumers with specific needs that continue to develop over time.

Research with the title The impact of e-commerce on the success of the microenterprise retail sector of the Pinhal Interior Norte sub-region of Portugal [9]. The purpose of this study is to find out whether the micro-businesses of the retail sector of the Pinhal Interior Norte sub-region, with involvement in the $\mathrm{EC}$, in the $\mathrm{B} 2 \mathrm{C}$ relationship, have an increased success rate due to their adoption and maintenance.

Research with the title Analysis of the logistics of home delivery of food and household goods. Implementation in Consumed in the Valencia area. Proposals for improvement [10]. The aim of this study is to analyze the main characteristics of home distribution services in large cities, which have been studied very little in urban logistics, with a view to proposing measures that will guarantee their economic, social and environmental sustainability.

Research entitled Understanding the diversity of final delivery solutions for online retailing: A case of Shenzhen, China [11]. The purpose of this study is to understand the spatial diversity of the final e-commerce shipping in Shenzhen city. The popularity of home delivery related to internet shopping has encouraged all stakeholders to accommodate current major trends.

Research titled Kansei engineering for e-commerce sunglasses selection in Malaysia [12]. This paper reports the application of Kansei Engineering Type 1 to identify the design elements of sunglasses that are emotionally attractive to demographers aged 18 to 34 years in Malaysia. This research makes a significant contribution to use in the sunglasses e-commerce industry as a value-added tool in eyewear-specific ecommerce.

\section{RESEARCH METHODS}

The research method used consisted of five stages. The stages are data collection, analysis, design, implementation, and evaluation. Fig. 1 is a diagram of a research flow chart.

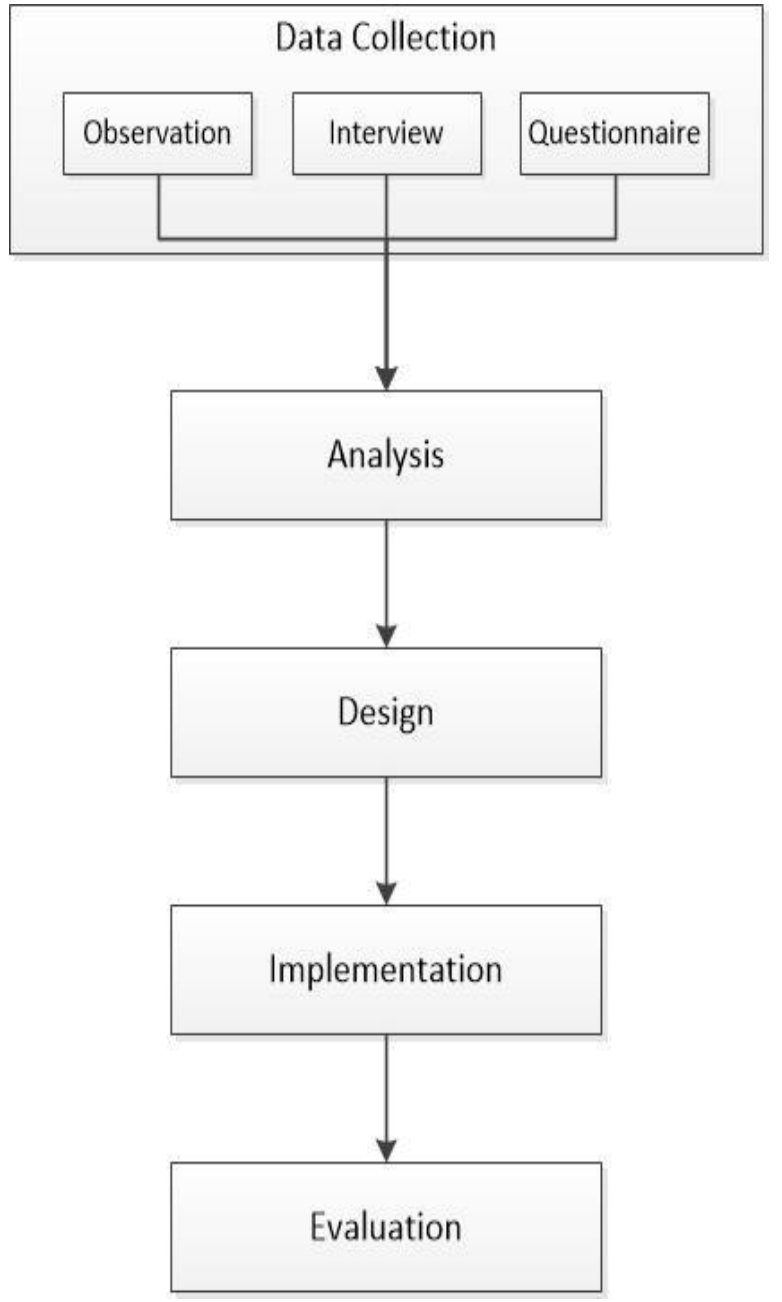

Fig. 1. Research methodology

\subsection{Data Collection}

The method used in data collection is observation, interview and questionnaire. Field Observation is a direct observation of the business process of buying and selling students in meeting their needs. Interviews were conducted to obtain data from respondents. Respondents involved were: Students, lecturers, and employees. Data that has been taken by interview is about the products that students need and how to fulfill them. Questionnaires are questions raised by researchers to respondents relating to online shopping habits and buying and selling activities.

\subsection{Analysis}

Data that has been collected through observation and interviews is then analyzed to produce system requirements at the analysis stage. Analysis is the stage of analyzing data to produce a functional and nonfunctional specification of the campus stalls application to be developed.

\subsection{Design}

System design is the stage for designing campus stall application system products that want to be developed. Activities in this design include menu design, use case diagrams, database design, system interface design. This design activity is based on the functional and non-functional specifications of the system generated from the previous activity (analysis phase). 


\subsection{Implementation}

The implementation phase is the stage to change the design into a program (coding). The result of this activity is the campus stall application system.

\subsection{Evaluation}

The evaluation phase is the stage to test whether the system developed can run well and meet user needs. Evaluation is done through black box testing and usability testing to produce good criteria.

\section{DISCUSSION}

\subsection{Analysis Requirement}

Systems analysis can be defined as the decomposition of a whole information system into its component parts. Identification and evaluation of the problems that occur and the needs so that the system can be made in accordance with expected. Campus Stalls is a marketplace application used for buying and selling to meet student needs.

At this stage an analysis is carried out to determine the functional and nonfunctional requirements of the marketplace system for the needs of students.

Functional Requirement: Is a requirement that is related to the processes and features that exist in the campus marketplace system.

1. The system can receive input data and display member data

2. The system can manage members' dashboard menus and sub menus.

3. The system can input data collection and display ad categories.

4. The system can accept input and display advertising photo data and other information.

5. The system can receive input and display many photos from some ads.

Non Functional Requirement: The need to focus on the behavioral properties possessed by the marketplace system.

1. The system can run on several web browsers such as Mozilla, Internet Explorer, Chrome, and others.

2. The system must be able to ensure that access to information is carried out by authorized users.

3. The system must be able to restore data for users who forget their password.

4. The system has an easy to understand interface

\subsection{Use Case Diagram}

Use case diagrams illustrate how a person or actor will use and utilize the system. Campus Stalls is a marketplace application whose users are divided into two parts. These users are members and admin. Figure 2 is a member use case diagram.

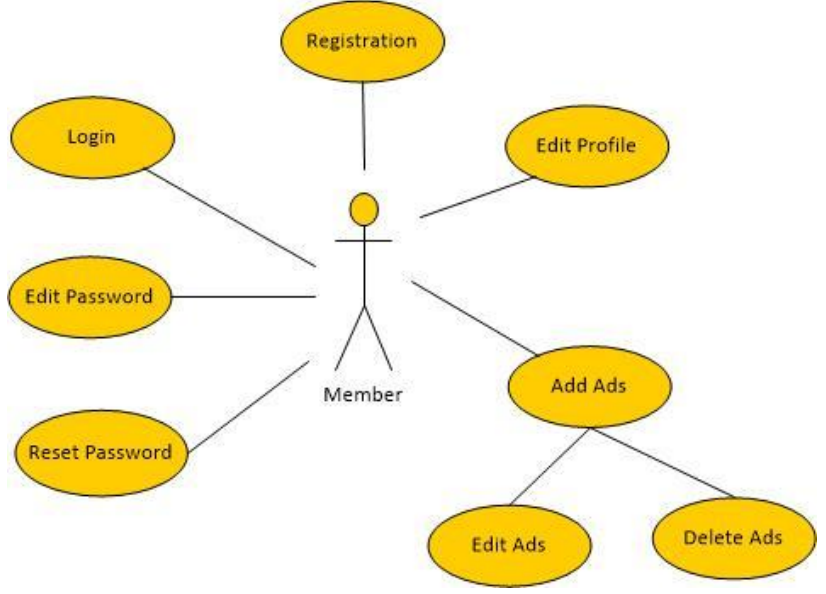

Fig. 2. Use Case of Member

Figure 2 is a member use case diagram. Members can login, reset passwords, register advertisements, edit profiles, and edit passwords. Apart from user members, other users are administrators. Fig. 3 below is the use case diagram from the administrator.

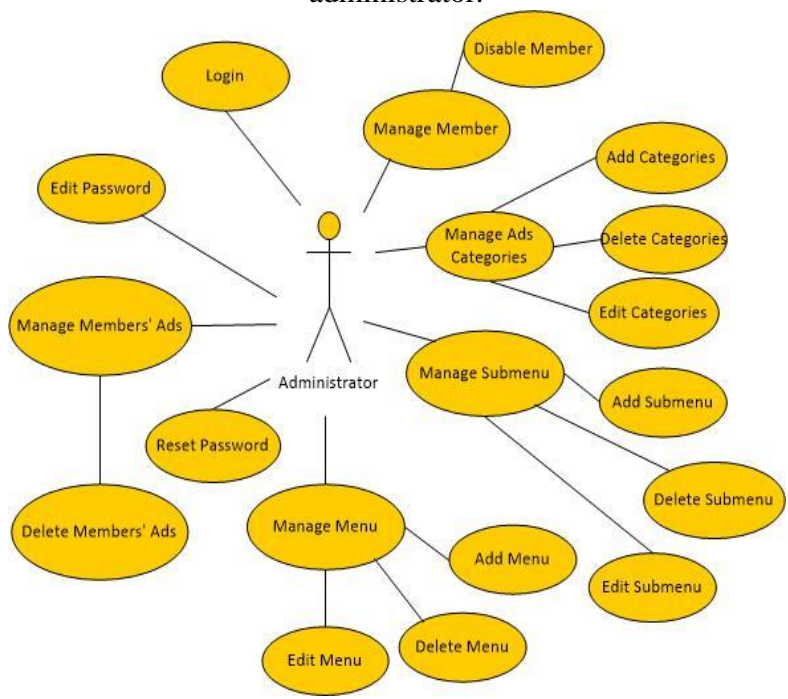

Fig. 3. Use Case of Administrator

Administrators can login into system, manage members, manage ads categories, manage submenus, manage menus, manage member adverts, edit profiles, and edit passwords.

\subsection{Implementation}

The implementation phase is the stage of application development by coding. This stage produces a campus kiosk system that is used to promote the sale of goods via the web. Based on the use case diagram that has been made, the user of this application consists of members and administrators. Each user has a different look and feature. Users can access the menu of members or administrators by first logging into the system. Login page can be seen in the Fig. 4 of the following. 


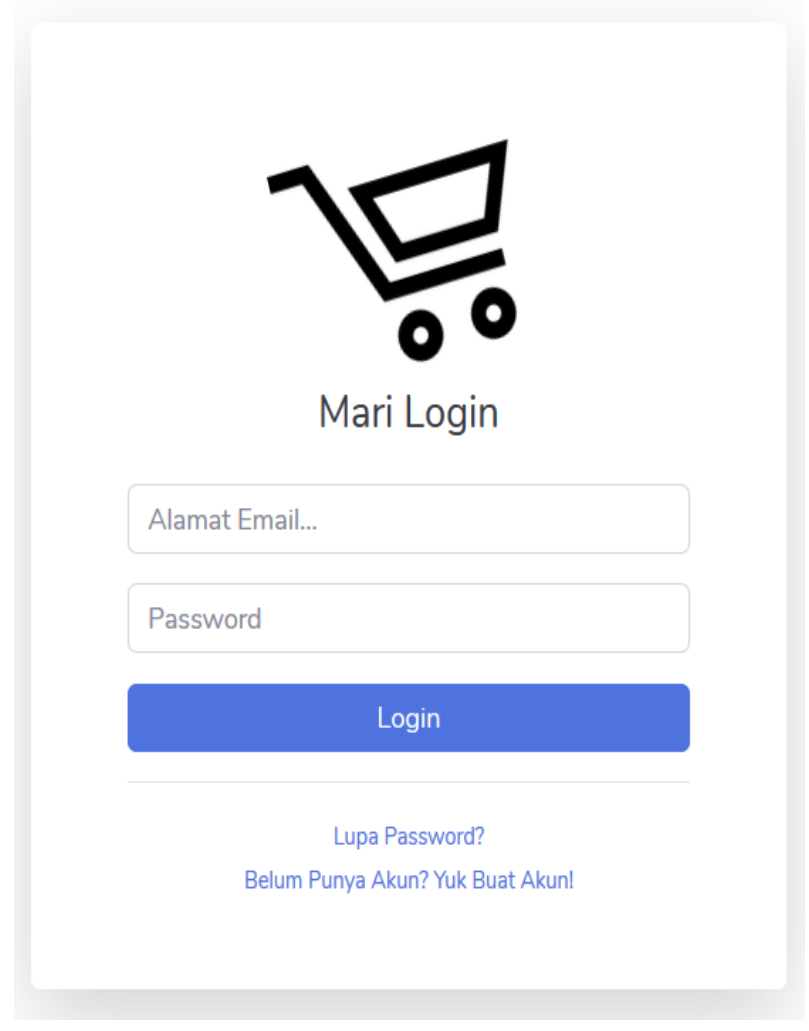

Fig. 4. Login Page

After the user logs in, the user will enter the dashboard page. The appearance of the dashboard page for administrators looks like in Fig. 5 of the following.

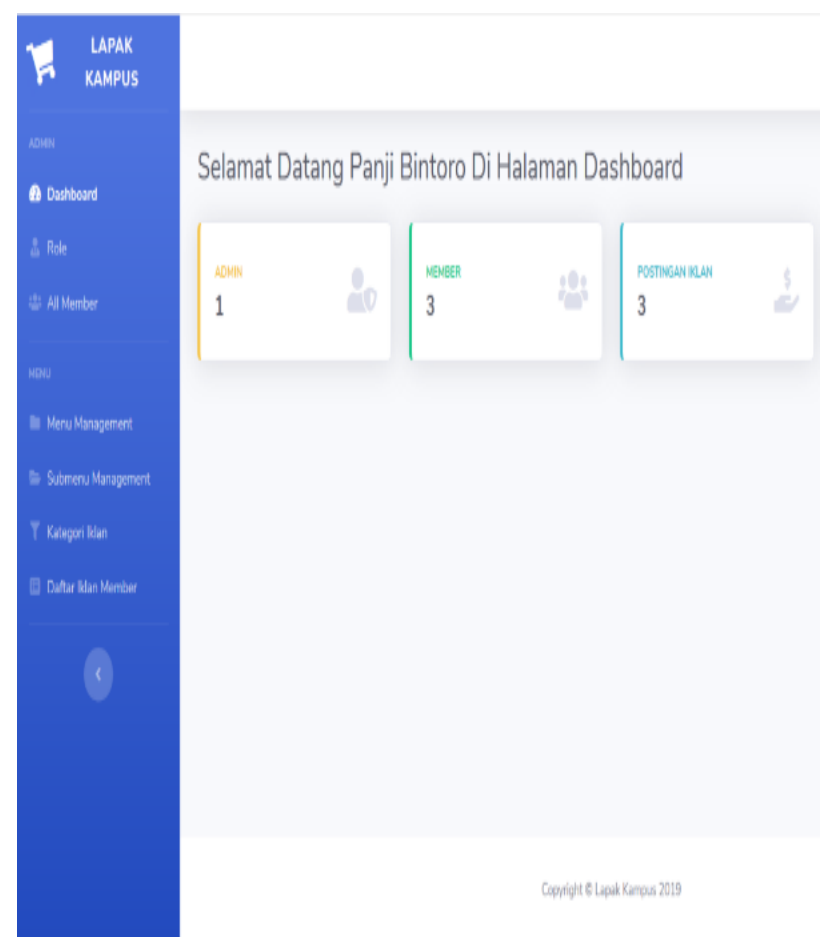

Fig. 5. Administrator Dashboard Page

The menu contained in the administrator dashboard is the role menu used to determine how member roles access, manage menus and submenus, display member data, advertisements from members, and ads categories.
The dashboard on the administrator is different from the dashboard on the member. The dashboard member page looks like in fig. 6 of the following.

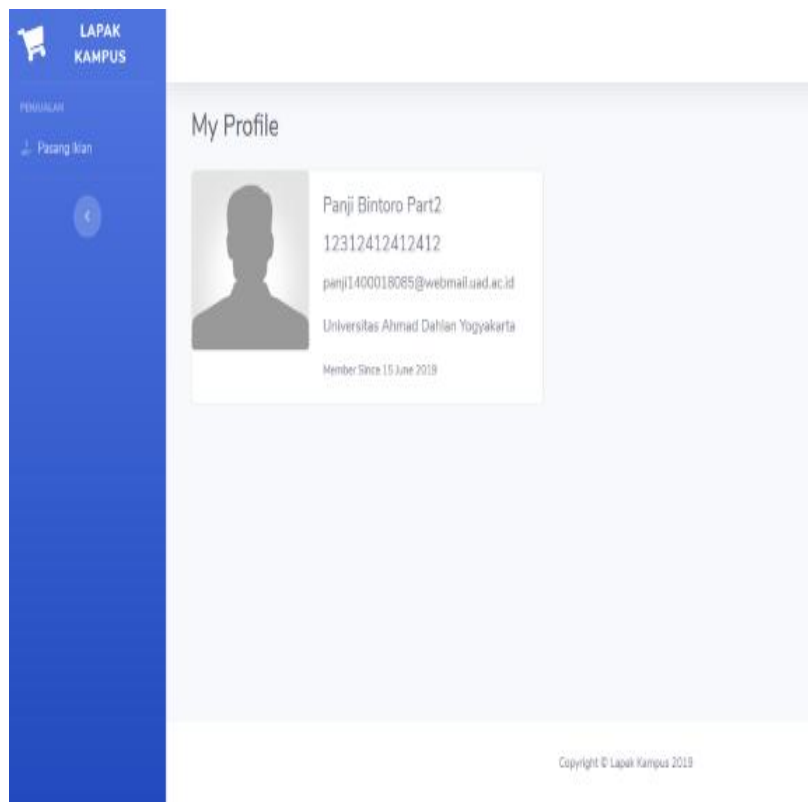

Fig. 6. Member Dashboard Page

The member dashboard has an account management menu such as edit profile and edit password. The other menu is a menu for managing ads. Members can add advertisements, edit and delete them through this menu. Member ad data is displayed on the ad page as in Fig. 7 of the following.

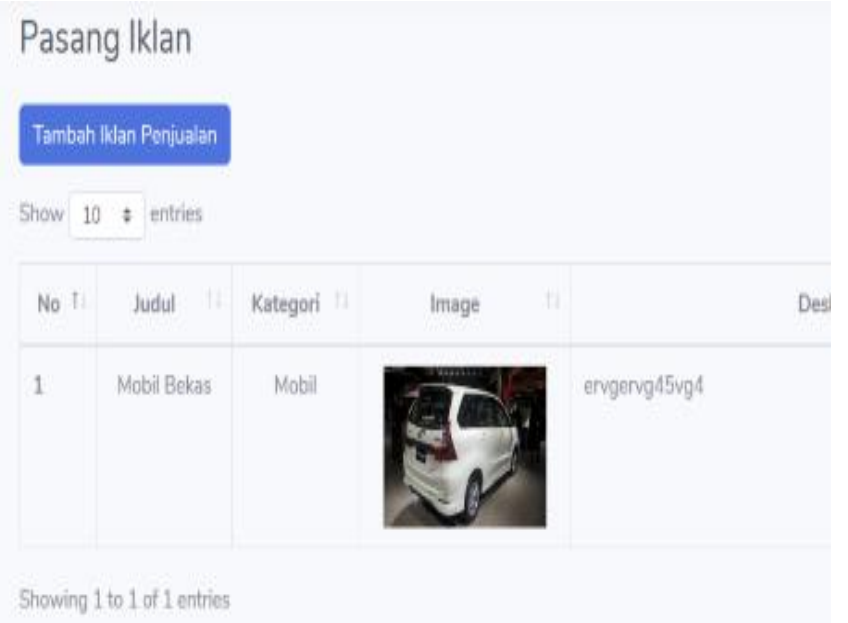

Fig 7. The Page of Ads

The advertisement page can be used to add advertisements regarding items to be sold by members. Members can add several pictures of products to sell.

\subsection{Evaluation}

The evaluation phase is carried out to find out the results or performance of the Campus Stall application. Evaluation is done by testing to find out whether the system developed is in 
accordance with needs. This test is carried out in two ways, the black box test and the usability test.

Black box test is done to test whether the features of the campus stalls application are running well. Testing is done by accessing each feature and see the results are in accordance with the expected target. If the results are as expected, the feature has run well. In the Black box test, there are 8 questions that are useful for testing the features available in the campus stalls application. The black box test results can be seen in table 1 below.

Table 1. Black Box Tests Result

\begin{tabular}{|c|c|c|c|}
\hline \multirow{2}{*}{ Number } & \multirow{2}{*}{ Question } & \multicolumn{2}{|c|}{ Answer } \\
\hline & & Yes & No \\
\hline 1 & Is the login going well? & $\checkmark$ & \\
\hline 2 & $\begin{array}{l}\text { Is the registration } \\
\text { process going well? }\end{array}$ & $\checkmark$ & \\
\hline 3 & $\begin{array}{l}\text { Is the password reset } \\
\text { menu running well? }\end{array}$ & $\checkmark$ & \\
\hline 4 & $\begin{array}{c}\text { Is the role menu } \\
\text { management going well? }\end{array}$ & $\checkmark$ & \\
\hline 5 & $\begin{array}{l}\text { Is the user menu and sub } \\
\text { menu management } \\
\text { going well? }\end{array}$ & $\checkmark$ & \\
\hline 6 & $\begin{array}{l}\text { Is member management } \\
\text { going well? }\end{array}$ & $\checkmark$ & \\
\hline 7 & $\begin{array}{l}\text { Is the ad category data } \\
\text { management going well? }\end{array}$ & $\checkmark$ & \\
\hline 8 & $\begin{array}{l}\text { Is the ad data processing } \\
\text { going well? }\end{array}$ & $\checkmark$ & \\
\hline
\end{tabular}

Black box test results are shown in table 1, all 8 questions have been answered with a "yes" statement. This means that all features in the campus stall application have been running well and have met the needs of the system.

The second test is usability testing. Usability testing is also carried out to find out whether campus stalls meet user needs. There are 10 questions on usability testing that are used to measure the level of comfort and ease of use. Each question on the questionnaire has a variety of answers that indicate a score on a scale of 1 to 5 . Usability testing is done by giving questions in the form of questionnaires to users. 10 randomly selected users to try to use web campus stalls are then asked to answer questions on the questionnaire. The test results are presented in table 2 below.

Table 2. Usability Tests Result

\begin{tabular}{|c|c|c|}
\hline $\begin{array}{c}\text { Numbe } \\
\mathbf{r}\end{array}$ & Statement & $\begin{array}{c}\text { Answer } \\
\text { score }\end{array}$ \\
\hline 1 & Website is easy to operate & 4,6 \\
\hline 2 & $\begin{array}{c}\text { The interaction on the web is clear } \\
\text { and understandable }\end{array}$ & 4,7 \\
\hline 3 & $\begin{array}{c}\text { The web has an attractive } \\
\text { appearance }\end{array}$ & 4,5 \\
\hline 4 & $\begin{array}{c}\text { Information layout on the web is } \\
\text { arranged properly }\end{array}$ & 4,6 \\
\hline
\end{tabular}

\begin{tabular}{|c|c|c|}
\hline $\begin{array}{c}\text { Numbe } \\
\mathbf{r}\end{array}$ & Statement & $\begin{array}{c}\text { Answer } \\
\text { score }\end{array}$ \\
\hline 5 & Web navigation can be done easily & 4,6 \\
\hline 6 & $\begin{array}{c}\text { Users can find the information } \\
\text { they are searching easily }\end{array}$ & 4,5 \\
\hline 7 & $\begin{array}{c}\text { Presentation of information on the } \\
\text { web has met user needs }\end{array}$ & 4,6 \\
\hline 8 & $\begin{array}{c}\text { Text on the web can be read } \\
\text { clearly }\end{array}$ & 4,7 \\
\hline 9 & $\begin{array}{c}\text { The web component is presented } \\
\text { according to user needs }\end{array}$ & 4,6 \\
\hline 10 & $\begin{array}{c}\text { There are no errors in running the } \\
\text { website }\end{array}$ & 4,8 \\
\hline & Average & 4,62 \\
\hline
\end{tabular}

The score from the usability test is 4.62 from a scale of 5 . These results indicate that the campus stalls application has met user needs.

\section{CONCLUSSION}

Campus stalls application: a marketplace for student needs has been successfully developed to support the activities of buying and selling transactions in order to meet the needs of students. The campus stalls application has been designed and implemented on a limited trial scale by obtaining a score of 4.62 from a scale of 5. This trial has shown that the web marketplace has met the needs based on an analysis of system requirements.

\section{ACKNOWLEDGMENTS}

Thanks to the Institute of Research and Community Service of Universitas Ahmad Dahlan has facilitated,.

\section{REFERENCES}

[1] J. Yang and P. Lin, "The Journal of Systems and Software A mobile payment mechanism with anonymity for cloud computing," J. Syst. Softw., vol. 116, pp. 6974, 2016.

[2] B. Robi'in, L. A. Wardana, and Suyoto, "New Solutions for Instant Payment Problems in Indonesia," Int. J. Adv. Sci. Eng. Inf. Technol., vol. 7, no. 4, pp. 1191-1197, 2017.

[3] M. M. Cruz-cunha, J. Varajão, I. Miranda, and N. Lopes, "An e-Marketplace of Healthcare and Social Care Services : the perceived interest," Procedia Technol., vol. 5, pp. 959-966, 2012.

[4] M. Hu, F. Huang, H. Hou, Y. Chen, and L. Bulysheva, "Customized logistics service and online shoppers ' satisfaction : an empirical study," Internet Res., vol. 26, no. 2, pp. 484-497, 2016.

[5] E. Pantano and C. V. Priporas, "The effect of mobile retailing on consumers' purchasing experiences: A dynamic perspective," Comput. Human Behav., vol. 61, pp. 548-555, 2016.

[6] M. M. Ferreira, L., Miranda, I., Simoes, R., Cruz-Cunha, "GuiMarket specification using the Unified Modeling Language," Procedia - Procedia Comput. Sci., vol. 64, pp. 1263-1272, 2015. 
[7] M. Ardis, E. Hole, and J. Manfredonia, "Creating a Marketplace for Multidisciplinary Multi-university Systems Engineering Capstone Projects," Procedia Comput. Sci., vol. 16, pp. 1036-1042, 2013.

[8] V. Ahuja and D. Khazanchi, "Creation of a conceptual model for Adoption of Mobile Apps for shopping from E-Commerce sites-An Indian context," Procedia Procedia Comput. Sci., vol. 91, pp. 609-616, 2016.

[9] J. A. R. Pacheco de Carvalho, H. Veiga, C. F. Ribeiro Pacheco, and A. D. Reis, "Performance Evaluation of Laboratory Wi-fi Ieee 802.11a Wpa Point-to-multipoint Links," Procedia Technol., vol. 9, pp. 146-151, 2013.
[10] R. A. López, J. Vicente, and C. Ferrándiz, "Analysis of the logistics of home delivery of food and household goods . Implementation in Consum in the Valencia area . Proposals for improvement .," Transp. Res. Procedia, vol. 18, no. June, pp. 189-196, 2016.

[11] Z. Xiao, J. J. Wang, J. Lenzer, and Y. Sun, "Understanding the diversity of final delivery solutions for online retailing: A case of Shenzhen , China," Transp. Res. Procedia, vol. 25, pp. 985-998, 2017.

[12] N. Khean, A. Sivaji, and M. Mohamad, "Kansei engineering for e-commerce sunglasses selection in Malaysia," Procedia - Soc. Behav. Sci., vol. 97, pp. 707714, 2013. 